\title{
The role of a water bug, Sigara striata, in freshwater food webs
}

Freshwater food webs are dominated by aquatic invertebrates whose trophic relationships are often poorly known. Here, I used laboratory experiments to study the role of a water bug, Sigara striata, as a potential predator and prey in food webs of stagnant waters. Multiplechoice predation experiment revealed that Sigara, which had been considered mostly herbivorous, also consumed larvae of Chironomus midges. Because they often occur in high densities and are among the most ubiquitous aquatic insects, Sigara water bugs may be important predators in fresh waters. A second experiment tested the role of Sigara as a potential prey for 13 common invertebrate predators. Mortality of Sigara inflicted by different predators varied widely, especially depending on body mass, foraging mode (ambush/searching) and feeding mode (chewing/suctorial) of the predators. Sigara was highly vulnerable to ambush predators, while searching predators caused on average 8.1 times lower mortality of Sigara. Additionally, suctorial predators consumed on average 6.6 times more Sigara individuals than chewing predators, which supports previous results hinting on potentially different predation pressures of these two types of predators on prey populations. The importance of these two foraging-related traits demonstrates the need to move from body mass based to multiple trait based descriptions of food web structure. Overall, the results suggests that detailed experimental studies of common but insufficiently known species can significantly enhance our understanding of food web structure. 


\title{
The role of a water bug, Sigara striata, in freshwater food webs
}

\author{
April 28, 2014
}

\begin{abstract}
Jan Klecka
Laboratory of Theoretical Ecology, Biology Centre of the Academy of Sciences of the Czech Republic, v.v.i., Institute of Entomology, České Budějovice, Czech Republic

Department of Fish Ecology and Evolution, Eawag: Swiss Federal Institute of Aquatic Science and Technology, Kastanienbaum, Switzerland

E-mail: jan.klecka@entu.cas.cz
\end{abstract}

\begin{abstract}
Freshwater food webs are dominated by aquatic invertebrates whose trophic relationships are often poorly known. Here, I used laboratory experiments to study the role of a water bug, Sigara striata, as a potential predator and prey in food webs of stagnant waters. Multiple-choice predation experiment revealed that Sigara, which had been considered mostly herbivorous, also consumed larvae of Chironomus midges. Because they often occur in high densities and are among the most ubiquitous aquatic insects, Sigara water bugs may be important predators in fresh waters. A second experiment tested the role of Sigara as a potential prey for 13 common invertebrate predators. Mortality of Sigara inflicted by different predators varied widely, especially depending on body mass, foraging mode (ambush/searching) and feeding mode (chewing/suctorial) of the predators. Sigara was highly vulnerable to ambush predators, while searching predators caused on average 8.1 times lower mortality of Sigara. Additionally, suctorial predators consumed on average 6.6 times more Sigara individuals than chewing predators, which supports previous results hinting on potentially different predation pressures of these two types of predators on prey populations. The importance of these two foraging-related traits demonstrates the need to move from body mass based to multiple trait based descriptions of food web structure. Overall, the results suggests that detailed experimental studies
\end{abstract}


of common but insufficiently known species can significantly enhance our understanding of food web structure.

\section{Introduction}

The view of ecological communities as networks of interacting species has revolutionized research of community structure, stability and responses to environmental changes (Ings et al., 2009). Studies that combine modelling and field data are attempting to provide general explanations of mechanisms structuring natural communities (Bascompte et al., 2003; Beckerman, Petchey \& Warren, 2006; Bascompte \& Jordano, 2007; Petchey et al., 2008) and to predict their responses to various threats, such as climate change (Petchey, Brose \& Rall, 2010; O'Gorman et al., 2012) and habitat destruction (Melián \& Bascompte, 2002; Fortuna \& Bascompte, 2006). Having accurate and detailed information about trophic interactions of individual species forming food webs is a necessary condition for these attempts to succeed. Although the resolution of published food webs has increased considerably in recent years (Thompson, Dunne \& Woodward, 2012), trophic position of many common species remains uncertain. This is troubling because a vast body of theoretical research has shown that food web structure is a key to understanding food web dynamics (de Ruiter, Neutel \& Moore, 1995; McCann, Hastings \& Huxel, 1998). Limited knowledge of food web structure in individual habitats thus calls into question the reliability of predictions of consequences of climate change or habitat destruction on food web diversity and stability.

Freshwater food webs are dominated by invertebrates, such as adults and larvae of insects, many of them carnivorous. Predatory aquatic insects have been traditionally considered generalists (Peckarsky, 1982) and food web studies often include them in relatively low resolution. This approach runs the risk of missing many crucial details given the tremendous diversity of aquatic insects. For example, there is over 150 species of diving beetles (all of them predatory) in the Czech Republic (Boukal et al., 2007), where this study has been conducted. Tens of species can coexist locally (Klecka \& Boukal, 2011), possibly thanks to pronounced prey selectivity (Klecka \& Boukal, 2012). Selective feeding in predatory aquatic insects is characterized not only by interspecific differences in prey selectivity and diet breadth (Cooper, Smith \& Bence, 1985; Allan, Flecker \& McClintock, 1987; Culler \& Lamp, 2009; Klecka \& Boukal, 2012), but also by marked ontogenetic diet shifts (Woodward \& Hildrew, 2002; Klecka \& Boukal, 2012). Prey mortality results from the interaction of several key predator and prey traits, particularly 
body size, predator foraging behaviour and prey vulnerability traits, such as its ability of rapid escape (Klecka \& Boukal, 2013). The insect component of freshwater food webs is thus complex, but we are beginning to understand mechanisms structuring its interactions. The importance of predatory insects is underscored by findings of trophic cascades elicited by individual species, such as Dytiscus alascanus (Cobbaert, Bayley \& Greter, 2010) and Notonecta sp. (Arnér et al., 1998).

Although detailed laboratory studies have been performed with a range of species, descriptions of food web structure have relied mostly on gut contents analyses of field-collected specimens (Warren, 1989; Woodward \& Hildrew, 2002; Layer et al., 2010). The most serious downside of this approach is that it cannot be reliably used to study the diet of suctorial predators, such as water bugs (Heteroptera). Even recent studies rely on expert knowledge or previous literature data to infer trophic relationships of suctorial predators (e.g., Layer et al., 2010). This way of circumventing the problem of identifying prey of suctorial predators may be dangerous. Feeding relationships of most species are virtually unknown and existing literature provides conflicting information in many other cases, including a decades-long controversy about herbivorous or predatory nature of corixid bugs (Heteroptera: Corixidae) (Hutchinson, 1993; Popham, Bryant \& Savage, 1984) studied in this paper. Despite several early attempts at identification of prey remains in the gut of suctorial water bugs by techniques of molecular biology (Giller, 1982, 1984, 1986), little progress has been achieved (Tate \& Hershey, 2003; Morales et al., 2003). Modern molecular assays detecting prey DNA in the gut using species-specific markers have not yet been widely employed in freshwater predators, although they are increasingly used in terrestrial invertebrates (Günther et al., in press; Foltan et al., 2005; Symondson, 2002) and hold a significant promise for the future (Pompanon et al., 2012). In this situation, traditional laboratory experiments still offer a unique opportunity to obtain reliable high-resolution data on predator-prey interactions of individual species in freshwater food webs.

The aim of this study was to evaluate the role of a common freshwater insects, Sigara striata, in freshwater food webs. Sigara and other corixid water bugs are among the most ubiquitous and abundant aquatic insects (Schilling, Loftin \& Huryn, 2009) and often reach densities of tens (Tolonen et al., 2003) or even hundreds of individuals $m^{-2}$ (Bendell \& McNicol, 1995), but their trophic position is not well understood (Hutchinson, 1993). I performed two complementary experiments addressing this knowledge gap. First, I tested whether Sigara can consume seven locally abundant species of aquatic invertebrates. Second, I tested the mortality of Sigara water bugs caused by 13 common predatory insects 
(nine species, multiple life stages in three cases). The same set of species, both predators and prey, as in (Klecka \& Boukal, 2012, 2013) was used. The first experiment addressed a decades-old controversy concerning whether Sigara is strictly herbivorous (scraping algae from submerged vegetation, stones etc.) or whether it also feeds on other invertebrates. If carnivorous, Sigara could be an important freshwater predator because of its frequently very high population density.

\section{Methods}

\section{Experiments}

The water bug Sigara striata (Heteroptera: Corixidae) was collected in small pools in a reclaimed sandpit near Suchdol nad Lužnicí in South Bohemia, Czech Republic. Some of its potential predators and preys were collected at the same site and others in various small fishless water bodies close to the city of České Budějovice. Species were selected to represent a wide variety of regionally dominant species and to form a taxonomically and functionally diverse assemblage. Experiments were carried out in May and June 2007 in a climate room with a regular temperature cycle (day: max. $22^{\circ} \mathrm{C}$, night: min. $18^{\circ} \mathrm{C}$; mean $20^{\circ} \mathrm{C}$ ) and 18L:6D photoperiod. The experimental procedures followed Klecka \& Boukal $(2012,2013)$ and the same species of predators and prey, except for Sigara, were used. All animals were kept in the lab for $2-5$ days prior to the experiments to allow for acclimation to the laboratory conditions. Predators were fed daily ad libitum with prey different from Sigara (mainly larvae of Trichoptera) and starved for 24 hours prior to the experiment. Experiments were performed in plastic boxes filled with 2.5 litres of aged tap water (bottom dimensions $24 \times 16 \mathrm{~cm}$, water depth ca. $8 \mathrm{~cm}$ ). The vessels had no substrate on the bottom but contained simple perching sites formed by four stripes of white plastic mesh suspended vertically in the water column. The vessels were shielded by sheets of brown carton from all sides to prevent disturbance of the experiments.

The first experiment tested whether Sigara striata can feed on six species of invertebrates which cooccur with it frequently in natural habitats (Table 1). In each replicate, six juvenile Lymnaea snails, 10 Chironomus midge larvae, 10 Cloeon mayfly larvae, 10 Culex mosquito larvae, 10 adult Asellus isopods and 30 adult Daphnia cladocerans were introduced into a vessel with water (see above) and 10 Sigara individuals were added after ca. 10 minutes. Ten Sigara individuals were used to increase the chance of detecting predation even if it occurs only rarely. Six replicates with Sigara as a potential predator and six 
without Sigara were performed to compare prey mortality in the presence/absence of Sigara. Qualitative observations of Sigara and prey behaviour were conducted in the beginning of the experiment and than occasionally during the experiment. All Sigara individuals used in the experiment and a sample of all prey species were preserved in $80 \%$ ethanol, their body length excluding appendages was measured to nearest $0.1 \mathrm{~mm}$ and their body mass was weighed after 48 hours of drying at $50^{\circ} \mathrm{C}$.

The second experiment aimed to estimate mortality rate of Sigara inflicted by different predators (Table 2). In each replicate, ten adults of Sigara were released first and one predator was added after ca. 10 minutes. The number of surviving Sigara individuals was counted after 24 hours. All individuals of Sigara and the predators were used only once. Four control trials were run to evaluate natural mortality of Sigara; no individual died in any of these control trials, suggesting that mortality observed in the presence of predators was caused entirely by predation. All predators were preserved in $80 \%$ ethanol, their body length measured and their body mass weighed as in the first experiment. I also classified their microhabitat use and made qualitative observations of their behaviour during the experiments.

\section{Data analysis}

I used Bayesian methods to estimate predation rates of Sigara consuming other invertebrates in the first experiment. The same approach was used to estimate mortality rate of Sigara caused by different predators and to test the role of predator traits for Sigara mortality in the second experiment. Overdispersed binomial distribution and logistic link function was used in all cases.

To estimate predation rates of Sigara on different prey species, I used a model contrasting mortality rate of prey species $i$ in the presence of Sigara and in control trials without Sigara. This approach was needed because some prey species had non-zero mortality in the control trials. I assumed that mortality $m_{i}$ of prey $i$ depends on the presence of Sigara in a species-specific way. To account for overdispersion, I used a two-stage model:

$$
\begin{aligned}
& Y_{i} \sim \operatorname{Bin}\left(n_{i}, m_{i}\right) \\
& \operatorname{logit}\left(m_{i}\right)=a_{i}+b_{i} S_{i}+z_{i} \\
& z_{i} \sim N\left(0, \sigma^{2}\right)
\end{aligned}
$$

where $Y_{i}$ is the number of individuals of a prey species $i$ dying in an experiment, $n_{i}$ is the initial number of prey individuals, $m_{i}$ is the mortality of prey $i, a_{i}$ is the natural mortality of prey $i$ in the 
absence of Sigara, $b_{i}$ is the effect of the presence of Sigara on the mortality of prey $i, S_{i}$ denotes the presence of Sigara ( $S_{i}=1$ when Sigara was present, $S_{i}=0$ otherwise), and $z_{i}$ is the overdispersion term.

To estimate the mortality rate of Sigara caused by individual predators, I used a model where the mortality of Sigara is a function of predator species. Predator species was used as a random factor. Two-stage model accounting for overdispersion was used similarly as above:

$$
\begin{aligned}
& Y_{i} \sim \operatorname{Bin}\left(n_{i}, m_{i}\right) \\
& \operatorname{logit}\left(m_{i}\right)=a_{0}+b_{i}+z_{i} \\
& b_{i} \sim N\left(0, \sigma_{1}^{2}\right) \\
& z_{i} \sim N\left(0, \sigma_{2}^{2}\right)
\end{aligned}
$$

where $Y_{i}$ is the number of Sigara individuals dying in an experiment, $n_{i}$ is the initial number of individuals, $m_{i}$ is the mortality of Sigara, $a_{0}$ is the intercept, $b_{i}$ is the effect of predator $i$ on the mortality of Sigara and $z_{i}$ is the overdispersion term.

To estimate the dependence of Sigara mortality on predator traits, I used a hierarchical model where the mortality of Sigara $m_{i}$ is a function of predator species (a random factor) as in eq. 2. The mortality of Sigara further depends on a combination of several predator traits with additive effects at the scale of the linear predictor. Two-stage model accounting for overdispersion was used as above; linear predictor in eq. 3 contains all explanatory variables:

$$
\begin{aligned}
& Y_{i} \sim \operatorname{Bin}\left(n_{i}, m_{i}\right) \\
& \left.\operatorname{logit}\left(m_{i}\right)=a_{0}+a_{1}\left(\ln \left(w_{i}\right)-\ln (\bar{w})\right)+a_{2}\left(\ln \left(w_{i}\right)-\ln (\bar{w})\right)^{2}+a_{3} A_{i}+a_{4} B_{i}+a_{5} C_{i}+b_{i}+z_{i} \quad \text { (eq. } 3\right) \\
& b_{i} \sim N\left(0, \sigma_{1}^{2}\right) \\
& z_{i} \sim N\left(0, \sigma_{2}^{2}\right)
\end{aligned}
$$

where $Y_{i}$ is the number of Sigara individuals dying in an experiment, $n_{i}$ is the initial number of individuals, $m_{i}$ is the mortality of Sigara, $a_{0}$ is the intercept, $a_{1}, \ldots, a_{5}$ are parameters describing the effect of individual predator traits, $w_{i}$ is body mass of predator $i, \bar{w}$ is mean body mass of all predators (i.e., predator body mass is centered in eq. 3 ), $A_{i}$ is the foraging mode of predator $i\left(A_{i}=1\right.$ for ambush predators and $A_{i}=0$ for searching predators), $B_{i}$ is the feeding mode ( $B_{i}=1$ for ambush predators and $B_{i}=0$ for searching predators), $C_{i}$ is the microhabitat preference of predator $i\left(C_{i}=1\right.$ for ambush predators and $C_{i}=0$ for searching predators) and $z_{i}$ is the overdispersion term. The analysis of posterior parameter distributions revealed that parameters $a_{2}$ and $a_{5}$ were approximately zero; the corresponding 
terms in eq. 3 were dropped to obtain the reduced model reported in the results (Table 3 ).

Uninformative priors were used for all parameters in all models. Specifically, normal distribution with $\mu=0$ and $\sigma^{2}=10^{3}$ was used for all parameters (see code in the Electronic Supplementary Material for implementation). Model parameters were estimated using Markov Chain Monte Carlo (MCMC) simulations with three chains, each with $10^{6}$ steps with thinning of 100 ; i.e. $10^{4}$ values per chain. A burn-in of $2 \cdot 10^{3}$ steps was used in all cases. All data analyses were conducted in R 3.0.1 (R Core Team, 2013); Bayesian analysis was performed using JAGS (Plummer, 2003) through rjags package for R (Plummer, 2013); coda package for R (Plummer et al., 2006) was used to analyse the MCMC output and to perform convergence diagnostics. A complete set of the raw data and the code is available as Electronic Supplementary Material. Posterior distributions of all parameter estimates obtained using Gibbs sampling in JAGS are provided in Electronic Supplementary Material together with the results of convergence diagnostics and autocorrelation analysis of MCMC chains.

\section{Results}

Sigara consumed on average $95 \%$ of Chironomus midge larvae in the first experiment, while it did not feed on the remaining five species (Fig. 1). Direct observations confirmed that increased mortality of Chironomus midge larvae was indeed caused by consumption by Sigara and that they were captured alive and subsequently consumed. Sigara used its forelegs to grab Chironomus larvae on the bottom of the experimental vessel, then ascended to the water surface, where it pierced the cuticle of its prey with a proboscis and sucked out the majority of soft tissues in the Chironomus body. Only small part of the prey body was discarded after consumption.

Mortality of Sigara caused by individual predators varied widely (Fig. 2). The analysis of the role of predator traits for Sigara mortality showed that the mortality of Sigara depended on body mass, foraging mode and feeding mode of the predators. On average, larger predators caused higher mortality

of Sigara (Figure 3, Table 3). Parameter estimate for the quadratic term of predator body mass was around zero, which indicates that Sigara mortality increases in a logistic way (i.e., linearly at the scale of the linear predictor) within the range of predator body masses used in the experiment (Figure 3, Table 3). Interestingly, body mass played a significant role only when other predator traits were included; alone it explained only ca. $0.2 \%$ of variation in mortality rate. In addition to the effect of body mass, the data 
indicate that predator's foraging mode and feeding mode affect the mortality rate of Sigara. Model which included these traits in addition to body mass explained over $60 \%$ of variation in mortality rate (Table 3). As expected, ambush predators caused higher mortality of Sigara than searching predators (Fig. 3); 8.1 times higher when ambush and searching predators of average body mass are compared. Suctorial predators killed more individuals than chewing predators (Fig. 3); 6.6 times more when suctorial and chewing predators of average body mass are compared. On the other hand, microhabitat preference of predators had no effect on the mortality of Sigara (Table 3).

\section{Discussion}

This study demonstrates that our knowledge of trophic links in freshwater food webs in still insufficient and can be enhanced by detailed laboratory experiments. Food web theory has been attempting to shed light on mechanisms underlying the maintenance of biodiversity (de Ruiter, Neutel \& Moore, 1995; McCann, Hastings \& Huxel, 1998) and more recently also to predict the consequences of climate change (Petchey, Brose \& Rall, 2010; O'Gorman et al., 2012), habitat fragmentation (Melián \& Bascompte, 2002) and other threats to natural communities, as well to study ecosystem recovery (Layer et al., 2010). However, empiricists have been frequently critical of food web approaches especially because they have relied on very crude data (e.g., Polis, 1991). Early food web studies lumped species to broad functional groups (Cohen, Briand \& Newman, 1990) and although recent datasets have improved the resolution of food web descriptions considerably (Thompson, Dunne \& Woodward, 2012), there is still a large room for improvements and refinements. Although food web research has been theory-driven for several decades; changes in the availability of empirical data are responsible for many recent advances. When May (1972) reported that complexity decreases stability, he used a simple model where feeding links were assigned at random. It later turned out that non-randomness of feeding links and uneven distribution of interaction strength allow complex communities to persist (de Ruiter, Neutel \& Moore, 1995; McCann, Hastings \& Huxel, 1998). More detailed data collected over the past two decades led to the rediscovery of the key role of body size for food web structure (Elton, 1927; Brose et al., 2006), which has important implications for food web stability (Brose, Williams \& Martinez, 2006; Heckmann et al., 2012). New, even more detailed data can reveal additional hidden levels of complexity (Melián et al., 2011; Gilljam et al., 2011). Detailed observational studies of individual species are thus needed to drive future progress. 
Attempts to explain food web structure have recently used body size of predators and prey as a major factor deciding on who eats whom (Petchey et al., 2008; Williams, Anandanadesan \& Purves, 2010; Williams \& Purves, 2011). However, it is becoming clear that this approach is oversimplified and can be substantially improved by the inclusion of multiple species traits, mostly related to predator foraging behaviour, prey vulnerability, and microhabitat use of both predators and prey (Rohr et al., 2010; Rossberg, Brännström \& Dieckmann, 2010; Wirtz, 2012; Klecka \& Boukal, 2013). Mortality of Sigara in my experiment depended not only on predator's body mass, but also on its foraging mode (ambush/searching) and feeding mode (chewing/suctorial). Ambush predators were more efficient in capturing Sigara probably because Sigara is capable of rapid escape behaviour which may be more effective against searching predators. Suctorial predators also consumed more Sigara individuals than chewing predators. Both these results support conclusions reached in multiple-choice experiments with the same set of predators but a larger set of seven different prey species (Klecka \& Boukal, 2013).

Surprisingly, Sigara can also be an important predator in freshwater food webs because the first experiment revealed that it feeds on Chironomus midge larvae. The possibility that Sigara water bugs could be carnivorous has been debated for several decades (Popham, Bryant \& Savage, 1984; Hutchinson, 1993). Gut content analyses by Popham, Bryant \& Savage (1984) suggested considerable variation in feeding habits of bugs of the family Corixidae. Several genera, mostly of larger species, such as Corixa and Cymatia, seem to be mostly carnivorous. However, smaller species of a diverse genus Sigara seemed to feed on algae or detritus or on a mixed diet. This reportedly included some unspecified animal components (Popham, Bryant \& Savage, 1984). Other authors reported remains of microscopic invertebrates, namely rotifers, in the gut of Sigara (Hutchinson, 1993). Because these bugs are suctorial, only remains of very small organisms which are consumed completely can be found in the gut and majority of the gut contents is unidentifiable (Popham, Bryant \& Savage, 1984). Sigara in my experiment fed on Chironomus midge larvae larger than itself by sucking out their body fluids, while holding the prey using the forelegs. It is very unlikely that any identifiable remains could be detected in its gut. The possibility that Sigara could feed on larger invertebrates, including insect larvae, has been rarely considered. For example the review of Shaalan \& Canyon (2009) on predatory insects feeding on mosquitoes lists only one study reporting predation by Sigara hoggarica on mosquitoes (Alahmed, Alamr \& Kheir, 2009); all other hemipterans in their review were members of the family Notonectidae. Nevertheless, the ability to feed on large prey, even larger than the predator, seems to be common among suctorial predators 
(Klecka \& Boukal, 2013; Nakazawa, Ohba \& Ushio, 2013). They also kill on average larger amounts of prey than equally sized chewing predators, such as adult beetles or dragonfly larvae, which makes them potentially more likely to have stronger interactions with prey (Klecka \& Boukal, 2013). Unfortunately, because their diet cannot be reliably studied using gut content analyses, they are underrepresented in studies of food web structure. Given their high species diversity, numerical abundance and voraciousness, this limitation of data availability can significantly distort our understanding of the dynamics of freshwater food webs, especially in small fishless water bodies, where invertebrate predators dominate. It is plausible that Sigara is an important freshwater predator, because the abundance of Sigara can reach hundreds on ind. $m^{-2}$ (Bendell \& McNicol, 1995). This makes Sigara one of the most abundant insects in suitable habitats (Tolonen et al., 2003; Schilling, Loftin \& Huryn, 2009). Molecular gut content assays have been employed to study the diet of Notonecta water bugs (Heteroptera: Notonectidae) in several early studies with mixed results (Giller, 1982, 1984, 1986) and in narowly targeted studies to identify predators of mosquitoes (Morales et al., 2003; Ohba et al., 2010). Although these methods are not widely used, methodical advancements, such as next generation sequencing, hold promise for the future (Pompanon et al., 2012). At present, careful laboratory experiments thus remain the only viable option to evaluate the role of the whole group of suctorial predators in freshwater food webs. Supplementing gut content analyses with laboratory predation experiments is a feasible way to boost the reliability and resolution of next generation food web data.

Simple laboratory experiments, such as the ones presented here, are not without limitations. Specifically, they are conducted over short periods of time in small vessels with very simple structure. Shortterm measurements of consumption rates may not correlate well with long-term measures of per-capita interaction strenght (Wootton, 1997). Less clear is how the lack of habitat complexity in laboratory conditions affects prey selectivity of predators. Habitat structure in the natural environment may provide refuges for some prey species against some predators but not against others, as demonstrated in numerous experiments testing the effects of the presence or density of vegetation for the foraging success and selectivity of predatory fish (Eklöv \& Diehl, 1994; Horinouchi et al., 2009). The availability of perching sites also affects foraging behaviour and predation rates in damslefly larvae(Convey, 1988). Many other predators adjust their foraging strategies in response to habitat structure; e.g., Dytiscus larvae decrease their activity in structured environment and employ more strongly ambushing tactics than in simple environment(Michel \& Adams, 2009). It is not clear how the relative importance of different predators 
for the mortality of Sigara might differ under natural conditions from the results of my experiment. Importantly, Sigara water bugs often live in newly created water bodies lacking dense vegetation, which the simple experimental conditions may represent reasonably well. However, the experimental vessels contained no substrate on the bottom. Many chironomid midge larvae, including the ones used in the experiment, normally bury themselves in soft sediments on the bottom. This is likely to reduce the encounter rates of Sigara and Chironomus larvae under natural conditions. Estimating the potential of Sigara to exert predation pressure sufficient to control the population density of Chironomus in the field will thus require observational or experimental data collected under natural conditions.

The findings of this study, particularly predation by Sigara on Chironomus larvae and high vulnerability of Sigara to ambushing and suctorial predatory insects, have important implications for understanding the structure of freshwater food webs. In suitable habitats, Sigara water bugs could be a key resource for certain groups of predators and they may also inflict large predation pressure on chironomid midge larvae, and possibly other invertebrates. It has been recently proposed that Sigara hoggarica can regulate mosquito populations by consuming their larvae and pupae (Alahmed, Alamr \& Kheir, 2009). Although their trophic role is still not well understood, Sigara water bugs may thus represent a key group in many freshwater food webs. Another, perhaps trivial, conclusion is that understanding food web structure requires paying attention to details of biology of individual species. In this particular case, information about the possibility that Sigara water bugs may play an important role as predators of insect larvae could be gleaned from specialized natural history papers, which are usually not published in high-profile journals and are thus missed by most ecologists. Food web research can progress only if feeding links are assigned correctly and comprehensively with at least species-level resolution. Detailed experimental studies of uncharismatic non-model species may identify a number of unexpected but potentially important trophic links.

\section{Acknowledgements}

I am grateful to D.J.Wilkinson and R. Argiento for introducing me to Bayesian methods during the Applied Bayesian Statistics School in Pavia, Italy, 3.-7.9.2012. I would also like to thank Jan Havelka for providing laboratory space and David S. Boukal for access to equipment needed to conduct this study. 


\section{References}

Alahmed, S., Alamr, A. \& Kheir, S. (2009) Seasonal activity and predatory efficacy of the water bug Sigara hoggarica Poisson (Hemiptera: Corixidae) against the mosquito larvae Culex quinquefasciatus (Diptera: Culicidae) in Riyadh City, Saudi Arabia. Journal of Entomology, 6, 90-95.

Allan, A.S., Flecker, J. \& McClintock, N. (1987) Prey preference of stoneflies: sedentary vs mobile prey. Oikos, 49, 323-331.

Arnér, M., Koivisto, S., Norberg, J. \& Kautsky, N. (1998) Trophic interactions in rockpool food webs: Regulation of zooplankton and phytoplankton by Notonecta and Daphnia. Freshwater Biology, 39, 79-90.

Bascompte, J. \& Jordano, P. (2007) Plant-animal mutualistic networks: The architecture of biodiversity. Annual Review of Ecology, Evolution, and Systematics, 38, 567-593.

Bascompte, J., Jordano, P., Melián, C. \& Olesen, J. (2003) The nested assembly of plant-animal mutualistic networks. Proceedings of the National Academy of Sciences of the United States of America, 100, 9383-9387.

Beckerman, A., Petchey, O. \& Warren, P. (2006) Foraging biology predicts food web complexity. Proceedings of the National Academy of Sciences, 103, 13745-13749.

Bendell, B.E. \& McNicol, D.K. (1995) Lake acidity, fish predation, and the distribution and abundance of some littoral insects. Hydrobiologia, 302, 133-145.

Boukal, D., Boukal, M., Fikacek, M., Hajek, J., Klecka, J., Skalicky, S., Stastny, J. \& Travnicek, D. (2007) Katalog vodních brouků Čské republiky/Catalogue of water beetles of the Czech Republic. Klapalekiana, 43, 1-289.

Brose, U., Jonsson, T., Berlow, E., Warren, P., Banasek-Richter, C., Bersier, L.F., Blanchard, J., Brey, T., Carpenter, S., Blandenier, M.F., Cushing, L., Dawah, H., Dell, T., Edwards, F., Harper-Smith, S., Jacob, U., Ledger, M., Martinez, N., Memmott, J., Mintenbeck, K., Pinnegar, J., Rall, B., Rayner, T., Reuman, D., Ruess, L., Ulrich, W., Williams, R., Woodward, G. \& Cohen, J. (2006) Consumer-resource body-size relationships in natural food webs. Ecology, 87, 2411-2417. 
Brose, U., Williams, R. \& Martinez, N. (2006) Allometric scaling enhances stability in complex food webs. Ecology Letters, 9, 1228-1236.

Cobbaert, D., Bayley, S. \& Greter, J.L. (2010) Effects of a top invertebrate predator (Dytiscus alaskanus; Coleoptera: Dytiscidae) on fishless pond ecosystems. Hydrobiologia, 644, 103-114.

Cohen, J., Briand, F. \& Newman, C. (1990) Community Food Webs: Data and Theory. Springer.

Convey, P. (1988) Competition for perches between larval damselflies: the influence of perch use on feeding efficiency, growth rate and predator avoidance. Freshwater Biology, 19, 15-28.

Cooper, S., Smith, D. \& Bence, J. (1985) Prey selection by freshwater predators with different foraging strategies. Canadian Journal of Fisheries and Aquatic Sciences, 42, 1720-1732.

Culler, L. \& Lamp, W. (2009) Selective predation by larval Agabus (Coleoptera: Dytiscidae) on mosquitoes: Support for conservation-based mosquito suppression in constructed wetlands. Freshwater Biology, 54, 2003-2014.

Eklöv, P. \& Diehl, S. (1994) Piscivore efficiency and refuging prey: the importance of predator search mode. Oecologia, 98, 344-353.

Elton, C. (1927) Animal Ecology. Macmillan Co., New York, USA.

Foltan, P., Sheppard, S., Konvicka, M. \& Symondson, W.O. (2005) The significance of facultative scavenging in generalist predator nutrition: detecting decayed prey in the guts of predators using PCR. Molecular Ecology, 14, 4147-4158.

Fortuna, M. \& Bascompte, J. (2006) Habitat loss and the structure of plant-animal mutualistic networks. Ecology Letters, 9, 278-283.

Giller, P. (1982) The natural diets of waterbugs (Hemiptera-Heteroptera): electrophoresis as a potential method of analysis. Ecological Entomology, 7, 233-237.

Giller, P. (1984) Predator gut state and prey detectability using electrophoretic analysis of gut contents. Ecological Entomology, 9, 157-162.

Giller, P. (1986) The natural diet of the Notonectidae: field trials using electrophoresis. Ecological Entomology, 11, 163-172. 
Gilljam, D., Thierry, A., Edwards, F., Figueroa, D., Ibbotson, A., Jones, J., Lauridsen, R., Petchey, O., Woodward, G. \& Ebenman, B. (2011) Seeing double: size-based and taxonomic views of food web structure. Advances in Ecological Research, 45, 67-133.

Günther, B., Rall, B.C., Ferlian, O., Scheu, S. \& Eitzinger, B. (in press) Variations in prey consumption of centipede predators in forest soils as indicated by molecular gut content analysis. Oikos.

Heckmann, L., Drossel, B., Brose, U. \& Guill, C. (2012) Interactive effects of body-size structure and adaptive foraging on food-web stability. Ecology Letters, 15, 243-250.

Horinouchi, M., Mizuno, N., Jo, Y., Fujita, M., Sano, M. \& Suzuki, Y. (2009) Seagrass habitat complexity does not always decrease foraging efficiencies of piscivorous fishes. Marine Ecology Progress Series, $\mathbf{3 7 7}$, $43-49$.

Hutchinson, G. (1993) A Treatise on Limnology. IV. The Zoobenthos, vol. 4. John Wiley \& Sons, Inc.

Ings, T., Montoya, J., Bascompte, J., Blüthgen, N., Brown, L., Dormann, C., Edwards, F., Figueroa, D., Jacob, U., Jones, J., Lauridsen, R., Ledger, M., Lewis, H., Olesen, J., Van Veen, F., Warren, P. \& Woodward, G. (2009) Ecological networks - beyond food webs. Journal of Animal Ecology, 78, 253-269.

Klecka, J. \& Boukal, D. (2011) Lazy ecologist's guide to water beetle diversity: Which sampling methods are the best? Ecological Indicators, 11, 500-508.

Klecka, J. \& Boukal, D. (2012) Who eats whom in a pool? a comparative study of prey selectivity by predatory aquatic insects. PLoS ONE, 7, e37741.

Klecka, J. \& Boukal, D. (2013) Foraging and vulnerability traits modify predator-prey body mass allometry: freshwater macroinvertebrates as a case study. Journal of Animal Ecology, 82, 1031-1041.

Layer, K., Hildrew, A., Monteith, D. \& Woodward, G. (2010) Long-term variation in the littoral food web of an acidified mountain lake. Global Change Biology, 16, 3133-3143.

May, R.M. (1972) Will a large complex system be stable? Nature, 238, 413-414.

McCann, K., Hastings, A. \& Huxel, G. (1998) Weak trophic interactions and the balance of nature. Nature, 395, 794-798. 
Melián, C. \& Bascompte, J. (2002) Food web structure and habitat loss. Ecology Letters, 5, 37-46.

Melián, C., Vilas, C., Baldó, F., González-Ortegón, E., Drake, P. \& Williams, R. (2011) Eco-evolutionary dynamics of individual-based food webs. Advances in Ecological Research, 45, 225-268.

Michel, M.J. \& Adams, M.M. (2009) Differential effects of structural complexity on predator foraging behavior. Behavioral Ecology, 20, 313-317.

Morales, M.E., Wesson, D.M., Sutherland, I.W., Impoinvil, D.E., Mbogo, C.M., Githure, J.I. \& Beier, J.C. (2003) Determination of Anopheles gambiae larval DNA in the gut of insectivorous dragonfly (Libellulidae) nymphs by polymerase chain reaction. Journal of the American Mosquito Control Association, 19, 163-165.

Nakazawa, T., Ohba, S.y. \& Ushio, M. (2013) Predator-prey body size relationships when predators can consume prey larger than themselves. Biology Letters, 9, 20121193.

O'Gorman, E., Pichler, D., Adams, G., Benstead, J., Cohen, H., Craig, N., Cross, W., Demars, B., Friberg, N., Gislason, G., Gudmundsdottir, R., Hawczak, A., Hood, J., Hudson, L., Johansson, L., Johansson, M., Junker, J., Laurila, A., Manson, J., Mavromati, E., Nelson, D., Olafsson, J., Perkins, D., Petchey, O., Plebani, M., Reuman, D., Rall, B., Stewart, R., Thompson, M. \& Woodward, G. (2012) Impacts of warming on the structure and functioning of aquatic communities. Individual- to ecosystem-level responses. Advances in Ecological Research, 47, 81-176.

Ohba, S.Y., Kawada, H., Dida, G.O., Juma, D., Sonye, G., Minakawa, N. \& Takagi, M. (2010) Predators of Anopheles gambiae sensu lato (Diptera: Culicidae) larvae in wetlands, western Kenya: confirmation by polymerase chain reaction method. Journal of Medical Entomology, 47, 783.

Peckarsky, B.L. (1982) Aquatic insect predator-prey relations. BioScience, pp. 261-266.

Petchey, O., Beckerman, A., Riede, J. \& Warren, P. (2008) Size, foraging, and food web structure. Proceedings of the National Academy of Sciences, 105, 4191-4196.

Petchey, O., Brose, U. \& Rall, B. (2010) Predicting the effects of temperature on food web connectance. Philosophical Transactions of the Royal Society B: Biological Sciences, 365, 2081-2091. 
Plummer, M. (2003) JAGS: A program for analysis of Bayesian graphical models using Gibbs sampling. Proceedings of the 3rd International Workshop on Distributed Statistical Computing (DSC 2003). March, pp. 20-22.

Plummer, M. (2013) rjags: Bayesian graphical models using MCMC. R package version 3-11. URL http://CRAN.R-project.org/package=rjags

Plummer, M., Best, N., Cowles, K. \& Vines, K. (2006) CODA: Convergence diagnosis and output analysis for MCMC. R News, 6, 7-11.

URL http://CRAN.R-project.org/doc/Rnews/

Polis, G. (1991) Complex trophic interactions in deserts: an empirical critique of food-web theory. American Naturalist, 138, 123-155.

Pompanon, F., Deagle, B.E., Symondson, W.O., Brown, D.S., Jarman, S.N. \& Taberlet, P. (2012) Who is eating what: diet assessment using next generation sequencing. Molecular Ecology, 21, 1931-1950.

Popham, E.J., Bryant, M.T. \& Savage, A.A. (1984) The role of front legs of British corixid bugs in feeding and mating. Journal of Natural History, 18, 445-464.

R Core Team (2013) R: A Language and Environment for Statistical Computing. R Foundation for Statistical Computing, Vienna, Austria.

URL http://www.R-project.org/

Rohr, R., Scherer, H., Kehrli, P., Mazza, C. \& Bersier, L.F. (2010) Modeling food webs: exploring unexplained structure using latent traits. American Naturalist, 176, 170-177.

Rossberg, A., Brännström, Å. \& Dieckmann, U. (2010) How trophic interaction strength depends on traits. Theoretical Ecology, 3, 13-24.

de Ruiter, P., Neutel, A.M. \& Moore, J. (1995) Energetics, patterns of interaction strengths, and stability in real ecosystems. Science, 269, 1257-1260.

Schilling, E.G., Loftin, C.S. \& Huryn, A.D. (2009) Macroinvertebrates as indicators of fish absence in naturally fishless lakes. Freshwater Biology, 54, 181-202. 
Shaalan, E.S. \& Canyon, D. (2009) Aquatic insect predators and mosquito control. Tropical Biomedicine, 26, 223-261.

Symondson, W. (2002) Molecular identification of prey in predator diets. Molecular Ecology, 11, 627-641.

Tate, A.W. \& Hershey, A.E. (2003) Selective feeding by larval dytiscids (Coleoptera: Dytiscidae) and effects of fish predation on upper littoral zone macroinvertebrate communities of arctic lakes. Hydrobiologia, 497, 13-23.

Thompson, R., Dunne, J. \& Woodward, G. (2012) Freshwater food webs: towards a more fundamental understanding of biodiversity and community dynamics. Freshwater Biology, 57, 1329-1341.

Tolonen, K., Hämäläinen, H., Holopainen, I., Mikkonen, K. \& Karjalainen, J. (2003) Body size and substrate association of littoral insects in relation to vegetation structure. Hydrobiologia, 499, 179190.

Warren, P. (1989) Spatial and temporal variation in the structure of a freshwater food web. Oikos, 55, 299-311.

Williams, R., Anandanadesan, A. \& Purves, D. (2010) The probabilistic niche model reveals the niche structure and role of body size in a complex food web. PLoS ONE, 5, e12092.

Williams, R. \& Purves, D. (2011) The probabilistic niche model reveals substantial variation in the niche structure of empirical food webs. Ecology, 92, 1849-1857.

Wirtz, K. (2012) Who is eating whom? Morphology and feeding type determine the size relation between planktonic predators and their ideal prey. Marine Ecology Progress Series, 445, 1-12.

Woodward, G. \& Hildrew, A. (2002) Body-size determinants of niche overlap and intraguild predation within a complex food web. Journal of Animal Ecology, 71, 1063-1074.

Wootton, J.T. (1997) Estimates and tests of per capita interaction strength: diet, abundance, and impact of intertidally foraging birds. Ecological Monographs, 67, 45-64. 


\section{Tables}

Table 1: The list of species used as potential prey of Sigara striata and their traits. The same set of species but different individuals was used by Klecka \& Boukal $(2012,2013)$.

\begin{tabular}{lcccccc} 
& & \multicolumn{3}{c}{ Body length $(\mathrm{mm})$} & \multicolumn{3}{c}{ Body mass $(\mathrm{mg})$} & \\
\cline { 3 - 6 } Species & $\mathrm{N}$ & Mean & SD & Mean & SD & Microhabitat \\
\hline Asellus aquaticus adult & 10 & 7.21 & 0.99 & 1.69 & 0.38 & benthic \\
Chironomus sp. larva & 10 & 9.12 & 0.71 & 0.31 & 0.069 & benthic \\
Cloeon dipterum larva & 10 & 6.87 & 0.89 & 1.02 & 0.21 & benthic \\
Culex sp. larva & 10 & 8.92 & 0.41 & 0.62 & 0.17 & pelagic \\
Daphnia sp. adult & 20 & 2.21 & 0.19 & 0.041 & 0.029 & pelagic \\
Lymnaea stagnalis juvenile & 10 & $9.65^{*}$ & 0.77 & $7.84 \#$ & 2.01 & pelagic\$ \\
\hline
\end{tabular}

$\mathrm{N}=$ number of individuals measured and weighed, ${ }^{*}$ shell length measured, \# weighed without shell, \$ Lymnaea was crawling on the sides of the experimental vessels and on the suspended mesh. 
Table 2: The list of predators used in the experiment and their traits. The same set of species but different individuals was used by Klecka \& Boukal $(2012,2013)$.

\begin{tabular}{|c|c|c|c|c|c|c|c|c|}
\hline Species & $\mathrm{N}$ & \multicolumn{2}{|c|}{ Body length (mm) } & \multicolumn{2}{|c|}{ Body mass (mg) } & $\begin{array}{c}\text { Foraging } \\
\text { mode }\end{array}$ & Feeding mode & Microhabitat \\
\hline \multicolumn{9}{|l|}{ Coleoptera } \\
\hline Acilius canaliculatus L2 & 4 & 11.8 & 0.63 & 2.74 & 0.66 & ambush & suctorial & pelagic \\
\hline Acilius canaliculatus L3 & 4 & 22.2 & 1.75 & 14.66 & 4.70 & ambush & suctorial & pelagic \\
\hline Dytiscus marginalis adult & 4 & 31.7 & 0.89 & 528.43 & 50.88 & searching & chewing & benthic \\
\hline \multicolumn{9}{|l|}{ Hemiptera } \\
\hline Ilyocoris cimicoides adult & 4 & 13.9 & 0.60 & 34.43 & 6.85 & searching & suctorial & benthic \\
\hline Notonecta glauca adult & 5 & 15.3 & 0.44 & 39.43 & 8.08 & ambush & suctorial & pelagic \\
\hline \multicolumn{9}{|l|}{ Odonata } \\
\hline Anax imperator F-0 & 4 & 47.6 & 2.61 & 267.0 & 54.42 & ambush & chewing & pelagic \\
\hline
\end{tabular}

$\mathrm{L} 2=$ larvae of the second instar, $\mathrm{L} 3=$ larvae of the third instar, F-0 = larvae of the last instar, F-2 $=$ larvae of the second before the last instar, $\mathrm{N}=$ number of replicates. 
Table 3: Parameter estimates describing the dependence of Sigara striata mortality on predator traits. The "full model" contains all predator traits that were measured. Two parameters (a2 and a5) had mean estimated values close to zero. Removing the corresponding terms of the model gave the "reduced model". Explained variance is provided for mean and median parameter values. A model including only predator body mass explained $0.2 \%$ of variation in mortality rate.

Full model

Reduced model

\begin{tabular}{|c|c|c|c|c|}
\hline Parameter & Mean estimate (SE) & Median (95\% CI) & Mean estimate (SE) & Median (95\% CI) \\
\hline Intercept $(\mathrm{a} 0)$ & $-3.06(0.023)$ & $-3.02(-6.29,-0.08)$ & $-3.35(0.012)$ & $-3.32(-5.79,-1.08)$ \\
\hline Predator mass (linear; a1) & $1.05(0.006)$ & $1.02(0.02,2.30)$ & $1.00(0.004)$ & $0.98(0.13,1.96)$ \\
\hline Predator mass (quadratic; a2) & $-0.19(0.003)$ & $-0.19(-0.81,0.39)$ & - & - \\
\hline Foraging - ambush (a3) & $2.25(0.041)$ & $2.21(-2.26,7.03)$ & $2.38(0.014)$ & $2.38(-0.33,5.09)$ \\
\hline Feeding - suctorial (a4) & $2.20(0.018)$ & $2.14(-1.02,5.81)$ & $2.15(0.009)$ & $2.11(-0.29,4.77)$ \\
\hline Microhabitat - pelagic (a5) & $0.27(0.036)$ & $0.30(-4.45,4.79)$ & - & - \\
\hline SD interspecific & $2.24(0.012)$ & $2.04(1.13,4.46)$ & $1.89(0.004)$ & $1.77(1.04,3.42)$ \\
\hline SD intraspecific & $0.29(0.001)$ & $0.25(0.08,0.68)$ & $0.28(0.001)$ & $0.25(0.08,0.68)$ \\
\hline Explained variance (\%) & $64.1 \%$ & $64.3 \%$ & $63.2 \%$ & $63.3 \%$ \\
\hline
\end{tabular}




\section{Figure 1}

Mortality of six freshwater invertebrates in the presence/absence of Sigara striata.

Estimated proportion of prey individuals dying during a 24-hour long experiment. The initial number of prey individuals was six Lymnaea, 10 Chironomus, 10 Cloeon, 10 Culex, 10 Asellus and 30 Daphnia. In the predation treatment, 10 Sigara bugs were added. Large circles denote mean values and vertical bars are $95 \%$ credible intervals. Small circles show values observed in individual replicates. 


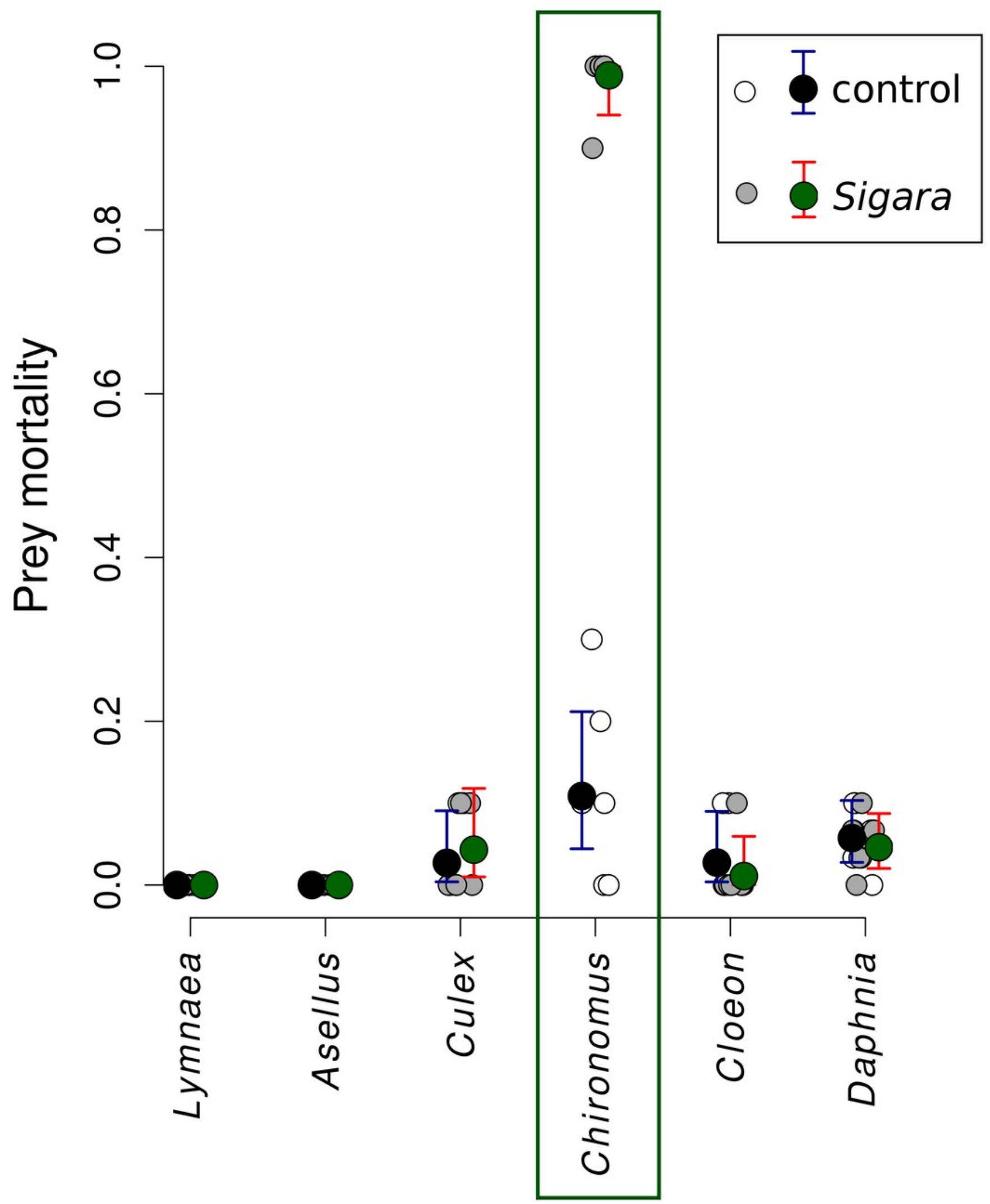




\section{Figure 2}

The mortality of Sigara striata caused by 13 different predators.

Estimated proportion of Sigara individuals killed by individual predators. Large green circles denote mean values, vertical bars are $95 \%$ credible intervals and small grey circles are individual observed values.

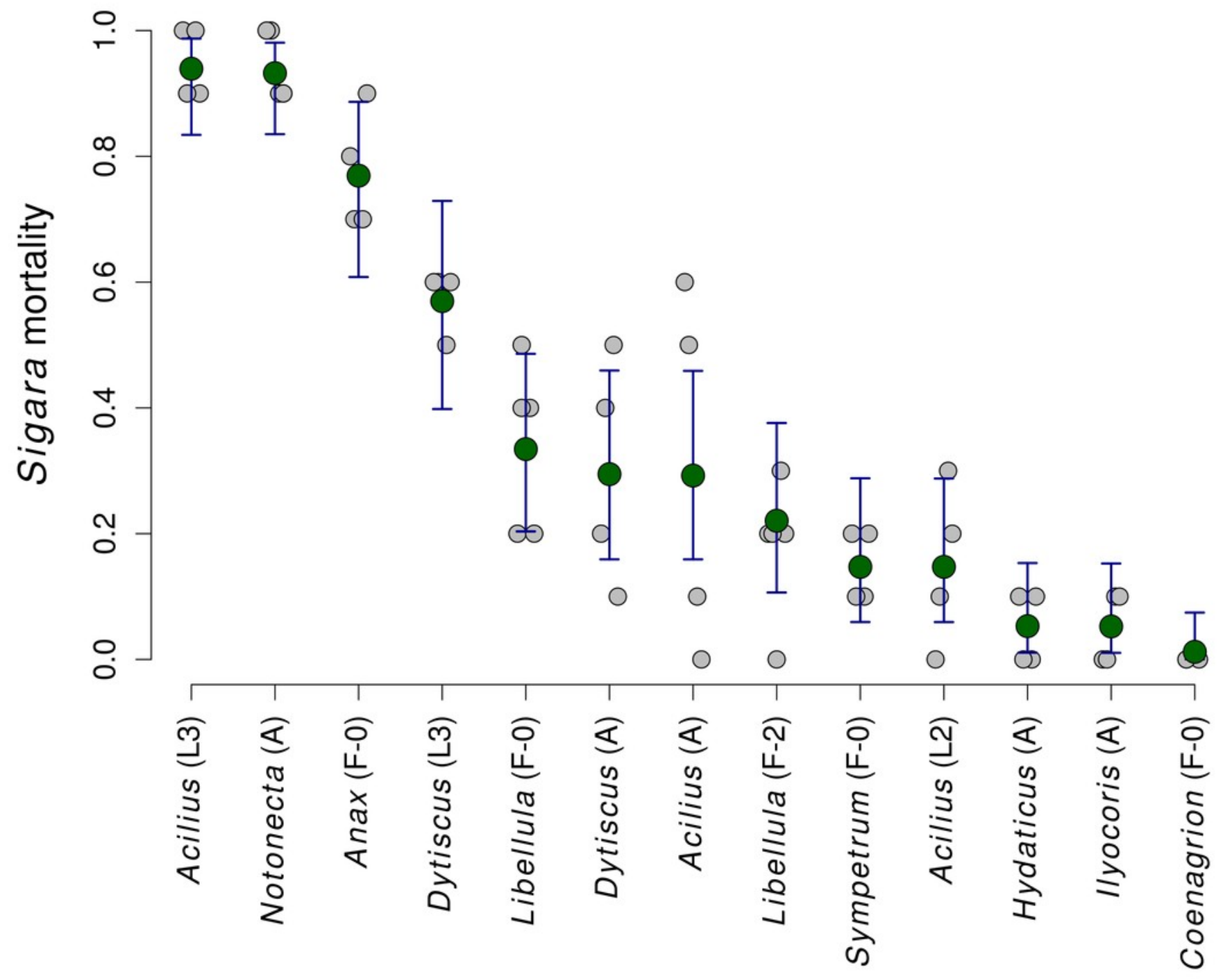




\section{Figure 3}

The dependence of the mortality of Sigara striata on predator traits.

Mortality of Sigara predicted by a model with predator body mass only (a) and with a combination of body mass, foraging mode and feeding mode (b). Black line in (a) shows model prediction and dotted line shows mean mortality. Lines in (b) show the predicted proportion of Sigara killed by a predator as a function of predator body mass, foraging mode and feeding mode. Small circles are mean values of Sigara mortality caused by individual predator species. Note that the x-axis has a logarithmic scale.
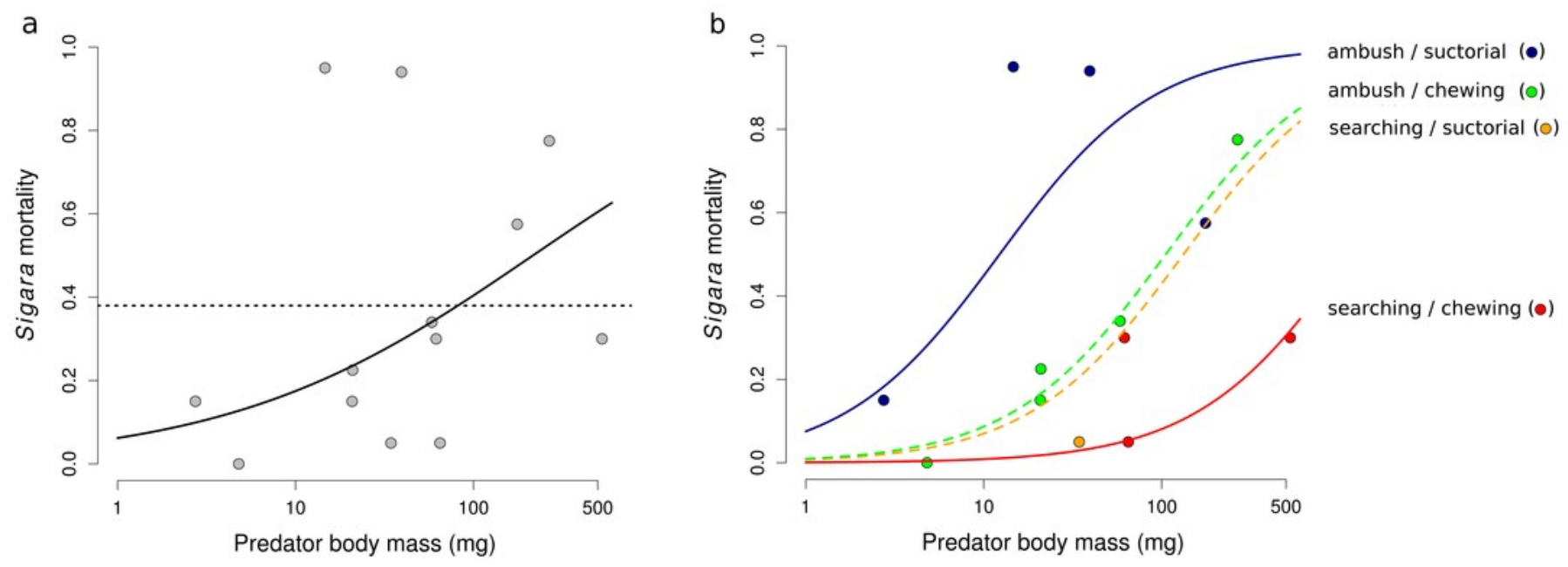